\title{
What do we need to eradicate rubella in the Islamic Republic of Iran?
}

\author{
F. Almassinokiani, ${ }^{7}$ S. Noorbakhsh, ${ }^{2}$ M. Rezaei, ${ }^{3}$ A. Almasi, ${ }^{4}$ H. Akbari, ${ }^{5}$ S. Asadolla ${ }^{7}$ P. Rahimzadeh ${ }^{6}$ and \\ M. Saberifard ${ }^{7}$
}

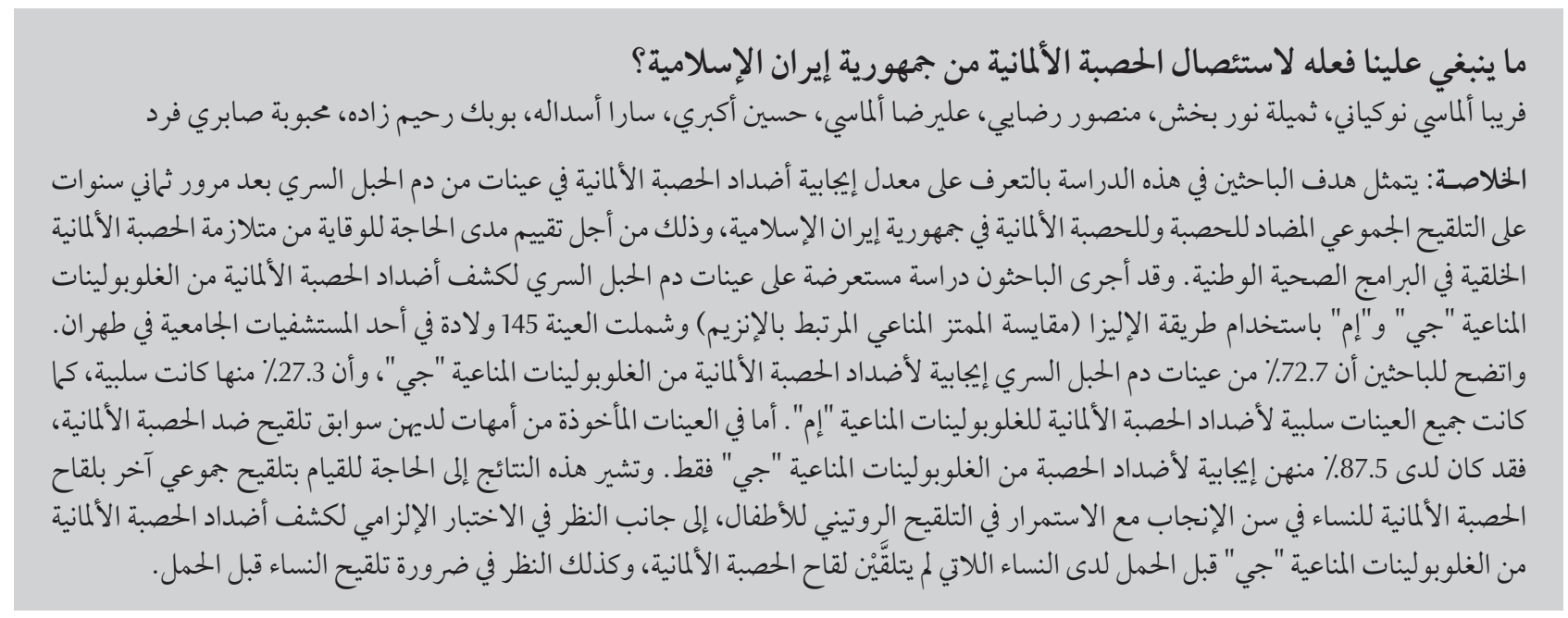

ABSTRACT To evaluate the need for congenital rubella syndrome prevention in our national health programme we aimed to determine the rate of anti-rubella positivity in umbilical cord blood samples 8 years after measlesrubella mass vaccination in the Islamic Republic of Iran. In a cross-sectional study we tested umbilical cord blood samples for anti-rubella IgG and IgM by ELISA in 154 deliveries at a university hospital in Tehran. Overall $72.7 \%$ of umbilical cord blood samples were positive for anti-rubella IgG and 27.3\% were negative. All of the samples were negative for anti-rubella IgM. In the samples with a history of mothers' rubella vaccination, only $87.5 \%$ were positive for anti-rubella IgG. The results suggest the need for another mass vaccination for rubella in women of child-bearing age and continuation of routine vaccination of infants, plus consideration of obligatory anti-rubella IgG testing before pregnancy in women who were not vaccinated and vaccination of women before marriage.

\section{De quoi avons-nous besoin pour éradiquer la rubéole en République islamique d'Iran ?}

RÉSUMÉ Pour évaluer la nécessité d'intégrer la prévention du syndrome de rubéole congénitale dans notre programme de santé national, nous avons tenté de déterminer le taux de positivité aux anticorps antirubéoleux dans des échantillons de sang de cordon ombilical huit ans après la campagne de vaccination de masse contre la rougeole et la rubéole en République islamique d'Iran. Au cours d'une étude transversale, nous avons utilisé la méthode ELISA pour analyser des échantillons de sang de cordon ombilical de 154 accouchements dans un hôpital universitaire de Téhéran afin de dépister des anticorps antirubéoleux de type lgG et IgM. Globalement, 72,7 \% des échantillons de sang de cordon étaient positifs pour les anticorps antirubéoleux de type IgG et 27,3\% étaient négatifs. Tous les échantillons étaient négatifs pour les anticorps antirubéoleux de type IgM. Seuls $87,5 \%$ des échantillons prélevés sur des mères ayant été vaccinées contre la rubéole étaient positifs pour les anticorps antirubéoleux de type IgG. Les résultats semblent indiquer la nécessité de mener une nouvelle campagne de vaccination de masse contre la rubéole chez les femmes en âge de procréer et de poursuivre la vaccination systématique des nourrissons, mais aussi d'envisager un test obigatoire de dépistage des anticorps antirubéoleux de type lgG avant une grossesse chez les femmes qui n'ont pas été vaccinées et la vaccination des femmes avant le mariage.

${ }^{7}$ Department of Obstetrics and Gynaecology; ${ }^{2}$ Department of Paediatrics; ${ }^{4}$ Department of Radiology; ${ }^{5}$ Department of Plastic and Reconstructive Surgery; ${ }^{6}$ Department of Anaesthesiology, Tehran University of Medical Sciences, Tehran, Islamic Republic of Iran (Correspondence to A. Almasi: dralmassi@yahoo.com). ${ }^{3}$ Department of Statistics, Kermanshah University of Medical Sciences, Kermanshah, Islamic Republic of Iran.

Received: 18/04/12; accepted: 25/06/12 


\section{Introduction}

Infection of pregnant women without immunity to the rubella virus at the early stages of pregnancy often induces abortion or congenital anomalies in the fetus, and is termed congenital rubella syndrome (CRS). Rubella immunization programmes are designed to prevent intrauterine rubella infection and lower the risk of future rubella outbreaks and CRS cases [1,2]. A report published in 1997 found that the proportion of women who remained susceptible to rubella was $\geq 25 \%$ in 12 developing countries [3]. Several meta-analyses have concluded that rubella immunization is a cost-effective means to reduce CRS in both developing and developed countries and has economic benefits comparable to those associated with hepatitis B vaccine and Haemophilus influenzae type $B$ vaccine [4-6].

Vaccination of children with mumps, measles and rubella (MMR) in Finland was started in 1982 and rubella had been eradicated by 1997 . Nevertheless, 25 years from the start of this programme, 6 cases of CRS were reported and the risk of rubella was increasing due to the growing numbers of the unvaccinated people in the population [7]. In Japan the number of CRS cases decreased remarkably after an immunization law revision in 1994 to change the focus of immunization from junior high-school girls to infants of both sexes [8]. In Poland vaccination of 13-year-old girls was introduced in 1989 , resulting in vaccination coverage of $95 \%$. Yet in 2003 among 1289 women investigated $10.5 \%$ did not have protective levels of anti-rubella antibodies [9]. In a survey in 2010 in 2 public schools in India $32.7 \%$ of $11-18$ yearold girls were seronegative and 100\% became seropositive post-vaccination [10].

In the Islamic Republic of Iran in December 2003 during a mass vaccination for measles-rubella (MR), more than 33 million doses of the vaccine were administered to 5-25-year-old males and females; $61.9 \%$ of vaccinees were immune against rubella before vaccination and $38.1 \%$ were susceptible. Of the susceptible group $98 \%$ acquired immunity against rubella after vaccination [11]. After this mass vaccination, MMR vaccination for 12 - and 18-month-old infants was instituted into our national health programme. The purpose of present study was to evaluate the seroprevalance of rubella antibodies in cord blood samples of newborn infants in Rasoul Akram hospital in Tehran University of Medical Sciences, to evaluate the need for CRS prevention in our national health programme 8 years after the mass vaccination against MR started.

\section{Methods}

In this cross-sectional, descriptiveanalytical study between September 2011 and January 2012 we had a total of 154 deliveries in Rasoul Akram university hospital which were sequentially included in the study. In all sera of cord blood samples, anti-rubella antibodies (IgG and IgM) were assayed by enzyme-linked immunosorbent assay (ELISA) method using Radim kits (Rubella IgG and IgM Radim EIA well) and interpretation was according to the manufacturer's instructions.

The data were analysed by SPSS, version 12, using histogram charts, mean and standard deviation (SD) and percentages. Chi-squared and Fisher exact tests were used for descriptive data analysis.

\section{Results}

The mothers' age range was $16-40$ years and their mean age was 25.1 (SD 5.6), mode 19 years (Figure 1). Almost half of the mothers (48.1\%) gave a history of 1 previous delivery. Mean gestational age was 37.1 (SD 2.8) weeks, range
21-41 weeks, and 10 (6.5\%) women were $\leq 32$ weeks.

Less than three-quarters (72.7\%) of the umbilical cord samples were positive for anti-rubella IgG and $27.3 \%$ were negative. All of the samples were negative for anti-rubella IgM. Of the mothers $64(41.6 \%)$ had no history of rubella vaccination and 90 (58.4\%) had been vaccinated. In those mothers who had been vaccinated for rubella (based on mother's recall) the rate of anti-rubella IgG in the umbilical cord blood was $87.5 \%(P=0.001)($ Table 1$)$.

In the 80 mothers aged $<25$ years the rate of anti-rubella IgG positivity in the umbilical cord blood was 54 (67.5\%) and in 74 mothers aged $25+$ years the rate of anti-rubella $\operatorname{Ig} G$ positivity was 58 (78.4\%) and there was no statistically significant difference between age and $\operatorname{IgG}$ positivity $(P=0.13)$.

\section{Discussion}

The rate of anti-rubella IgG positivity in umbilical cord blood samples in this study was $72.7 \%$ and all of the samples were negative for anti-rubella IgM. Just over half of mothers (58.4\%) had a history of rubella vaccination. In samples with a history of rubella vaccination in mothers, $87.5 \%$ were anti-rubella IgG positive. This is less than the immunization rate after the mass rubella vaccination campaign in 2003 (98\%) [11].

Findings of a 2003 study in the Islamic Republic of Iran indicated that $38.1 \%$ of vaccinees $(738 / 1940)$ were susceptible to rubella before vaccination (IgG avidity assay was used to evaluate the rubella immunity and $98 \%$ of the susceptible group (723/738) acquired immunity against rubella after vaccination [11]. The higher rate of seropositivity than in our study may be due to a number of reasons. First, in our study more than 8 years had passed since vaccination (antibody decay). Secondly, the women in our study were a sample of Iranian women giving birth; perhaps 


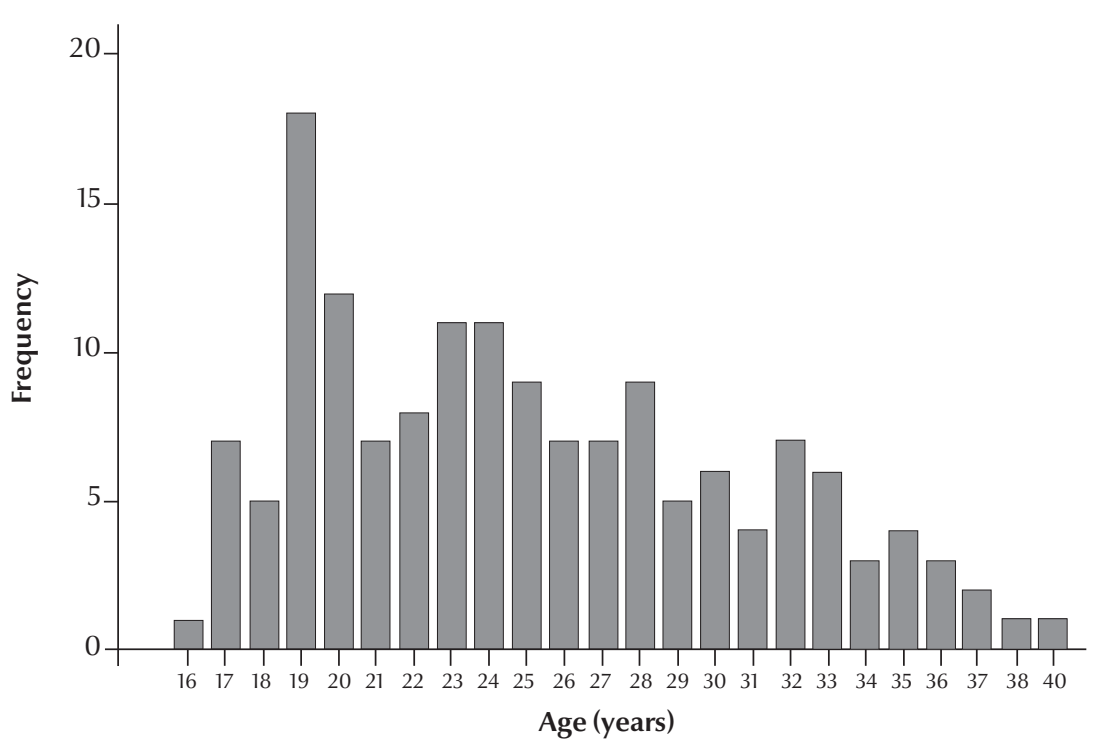

Figure 1 Age distribution of the study mothers

in another study with a larger population the results may be a little different. Thirdly, those people who participated in the rubella campaign were 13-33 years old at the time of the study, but some of our sampled women were out of this age range group. Although we had rubella mass vaccination 8 years ago for the age group 5-25 years followed by routine vaccination of all infants at 12 and 18 months, these infants have still not reached reproductive age. Therefore, this routine vaccination had not yet affected the rate of rubella in pregnant women. Now we have a situation in which some women in reproductive age that have not been vaccinated and also have not environmental immunity and are sensitive to rubella.

Vaccinations are one of the most important effective preventive means for protection against infective diseases. The high cost-benefit ratio of immunizations reduces public health costs. CRS leads to deafness, heart disease and cataract and a variety of other permanent manifestations. Rubella immunization programmes are designed to prevent intrauterine rubella infection. In 1969, the first rubella vaccine was licensed for use, and the US Centers for Disease Control and Prevention began its national CRS registry [12]. In 1969 the US established its national rubella vaccination programme; 32 years later, reports of rubella reached low numbers. The incidence of rubella decreased significantly from 0.1 per 100000 population in 1998 to 0.005 per 100000 population in 2004 [1-3]. In Greece in 1999 the incidence of CRS was 4 per 100000 live births and in 2003 , although $60 \%-80 \%$ of teenagers were vaccinated, $10 \%-20 \%$ of women of child-bearing age were susceptible to rubella [13]. In a survey in 2001 in

\begin{tabular}{|c|c|c|c|c|c|}
\hline \multirow[t]{2}{*}{ Vaccination history } & \multicolumn{2}{|c|}{ Negative IgG } & \multicolumn{2}{|c|}{ Positive IgG } & \multirow{2}{*}{$\begin{array}{c}\text { Total } \\
\text { No. }\end{array}$} \\
\hline & No. & $\%$ & No. & $\%$ & \\
\hline Positive & 6 & 12.5 & 56 & 87.5 & 64 \\
\hline Negative & 34 & 37.8 & 56 & 62.2 & 90 \\
\hline Total & 42 & 27.3 & 112 & 72.7 & 154 \\
\hline
\end{tabular}

Germany $37.6 \%$ of pregnant women had history of rubella vaccination and $86.6 \%$ of samples were IgG positive for rubella [14].

After mass vaccination for MR in 2003 in Islamic Republic of Iran, 98\% of the susceptible group that were IgG negative before vaccination became IgG positive for anti-rubella antibody [11]. In another study in our country $1-3$ months after MR mass vaccination, only $0.3 \%$ of vaccinated women had no rubella-specific IgG response [15]. In our study, the rate of anti-rubella $\operatorname{IgG}$ positivity in umbilical cord blood of babies whose mothers had a history of vaccination was $87.5 \%$. This decrease in the anti-rubella IgG positive rate in vaccinees may be due to antibody decay that is reported in other studies. Although some studies have shown that vaccination-induced rubella antibodies are detectable in almost all persons up to 16 years after successful vaccination [16], other studies have not. In a longitudinal study after MR vaccination a minimal antibody decay rate of $-2.9 \%$ was reported for rubella and it was suggested that 2 dose vaccination was needed to protect women from rubella infection [17]. In a study from Finland, antibody decay was determined 15 years after the second MMR dose and MMR-induced antibodies waned significantly after the second dose [18]. In Sweden 30 years after introduction of rubella vaccination and 22 years after starting MMR vaccination in the national health programme, IgG activity in antenatal sera was $95.8 \%$. It was suggested routine screening for rubella immunity prior to the first pregnancy and routine administration of additional dose of MMR vaccine to all young adults before they left the educational system [19]. In a survey from Turkey in 2006 anti-rubella $\operatorname{IgG}$ was positive in $95 \%$ and $\operatorname{IgM}$ in $0.5 \%$ of the tested women [20].

Positive antibody titres are significantly higher in those who receive 2 doses of MMR [21]. In the United Kingdom, rubella vaccination started 
in 1970 and in one study, the frequency of women with anti-rubella $\operatorname{IgG}<10$ $\mathrm{IU} / \mathrm{mL}$ increased by $60 \%$ over the 6-year study period [22]. In a survey in 1997 from 45 developing countries, the proportion of women who remained susceptible to rubella was $<10 \%$ in 13 countries (including the Islamic Republic of Iran, Oman, Kuwait, China, Chile, Saudi Arabia and Gambia) and $10 \%-24 \%$ in 20 countries and $\geq 25 \%$ in 12 countries (including Thailand, India, Malaysia, Singapore and Panama) [3]. In the current study the rate of antirubella $\operatorname{IgG}$ negativity in umbilical cord blood was high (27.3\%).

In our study all the samples were negative for anti-rubella IgM and this may be due to the small sample size. In a recent survey in the Islamic Republic of Iran the rate of CRS was estimated as 0.2 per 1000 live births [23]. In one survey from 2000-05 of 1954 Palestinian women attending for in vitro fertilization, positive results for anti-rubella $\operatorname{IgM}$ was $7 \%$ [24]. Therefore, rubella may still an important problem in the Islamic Republic of Iran.

In a WHO position paper on rubella vaccines, it was suggested that because of the high response rate to a single dose of rubella vaccine $(\geq 95 \%)$ routine injection of a second dose is not necessary and the Eastern Mediterranean Region has established a goal of CRS prevention without a target date for countries that had incorporated rubella vaccination in their national vaccination programmes [25].

\section{Conclusions}

Each country should assess its rubella situation and find appropriate ways to prevent CRS. The rate of anti-rubella IgG negative in umbilical cord blood samples in our study was $27.3 \%$, which is high, and the majority of cases were in unvaccinated women. This situation shows that a preventive CRS policy should be implemented in which the priority must be given to protection of women of child-bearing age. Our results suggest the need for another mass vaccination for rubella in women of child-bearing age and continuation of routine vaccination MMR of infants, plus consideration of obligatory antirubella $\operatorname{IgG}$ testing before pregnancy in women who have not been vaccinated and of MMR vaccination of women before marriage. An appropriate surveillance system is needed because without epidemiological data before the introduction of the rubella vaccine an adequate monitoring programme cannot be successful.

\section{Acknowledgements}

Funding: The study was supported by the Paediatrics Infectious Diseases Research Centre, Tehran University of Medical Sciences, Tehran, Islamic Republic of Iran.

Competing interests: None declared.

\section{References}

1. Reef SE et al. The epidemiological profile of rubella and congenital rubella syndrome in the United States, 1998-2004: the evidence for absence of endemic transmission. Clinical Infectious Diseases, 2006, 43(Suppl. 3):S126-S132.

2. Herrmann KL. Rubella in the United States: toward a strategy for disease control and elimination. Epidemiology and Infection, 1991, 107:55-61.

3. Cutts FT et al. Control of rubella and congenital rubella syndrome (CRS) in developing countries, Part 1: Burden of disease from CRS. Bulletin of the World Health Organization, 1997, 75:55-68.

4. Demicheli $\vee$ et al. Vaccines for measles, mumps and rubella in children. Cochrane Database of Systematic Reviews, 2005, (4):CD004407.

5. Robertson SE et al. Control of rubella and congenital rubella syndrome (CRS) in developing countries, Part 2: Vaccination against rubella. Bulletin of the World Health Organization, 1997, 75:69-80.

6. Hinman AR et al. Economic analyses of rubella and rubella vaccines: a global review. Bulletin of the World Health Organization, 2002, 80:264-270.

7. Peltola $\mathrm{H}$ et al. Measles, mumps, and rubella in Finland: 25 years of a nationwide elimination programme. Lancet Infectious Diseases, 2008, 8:796-803.

8. Katow S. Surveillance of congenital rubella syndrome in Japan, 1978-2002: effect of revision of the immunization law. Vaccine, 2004, 22:4084-4091.
9. Wysokiñska T et al. The prevalence of anti-rubella antibodies in women of childbearing age in Poland. Vaccine, 2004, 22:1899-1902.

10. Sharma $\mathrm{H}$ et al. Sero-surveillance to assess immunity to rubella and assessment of immunogenicity and safety of a single dose of rubella vaccine in school girls. Indian Journal of Community Medicine, 2010, 35:134-137.

11. Hamkar R et al. Evaluation of immunity against rubella in Iranian after mass campaign for measles-rubella vaccination on December 2003. American Journal of Infection Control, 2006, 34:588-592.

12. Edlich RF et al. Rubella and congenital rubella (German measles). Journal of Long-Term Effects of Medical Implants, 2005, 15:319-328.

13. Panagiotopoulos T, Georgakopoulou T. Epidemiology of rubella and congenital rubella syndrome in Greece, 1994-2003. Eurosurveillance, 2004, 9:17-19.

14. Sauerbrei A et al. Antibodies against vaccine-preventable diseases in pregnant women and their offspring in the eastern part of Germany. Medical Microbiology and Immunology, 2002, 190:167-172.

15. Hamkar R et al. Distinguishing between primary infection and reinfection with rubella vaccine virus by IgG avidity assay in pregnant women. Eastern Mediterranean Health Journal, 2009, 15:94-103.

16. Chu SY et al. Rubella antibody persistence after immunization. Sixteen-year follow-up in the Hawaiian Islands. Journal of the American Medical Association, 1988, 259:3133-3136. 
17. Kremer JR, Schneider F, Muller CP. Waning antibodies in measles and rubella vaccinees-a longitudinal study. Vaccine, 2006, 24:2594-2601.

18. Davidkin I et al. Persistence of measles, mumps, and rubella antibodies in an MMR-vaccinated cohort: a 20-year follow-up. Journal of Infectious Diseases, 2008, 197:950-956.

19. Kakoulidou $M$ et al. Serum levels of rubella-specific antibodies in Swedish women following three decades of vaccination programmes. Vaccine, 2010, 28:1002-1007.

20. Ocak S et al. Seroprevalence of Toxoplasma gondii, rubella and cytomegalovirus among pregnant women in southern Turkey. Scandinavian Journal of Infectious Diseases, 2007, 39:231-234.

21. Vandermeulen $C$ et al. Long-term persistence of antibodies after one or two doses of MMR-vaccine. Vaccine, 2007, 25:6672-6676.
22. Byrne L et al. Seroprevalence of low rubella IgG antibody levels among antenatal women in England tested by NHS Blood and Transplant: 2004-2009. Is rubella susceptibility increasing? Vaccine, 2012, 30:161-167.

23. Sadighi J, Eftekhar H, Mohammad K. Congenital rubella syndrome in Iran. BMC Infectious Diseases, 2005, 5:44.

24. Al-Hindi A, Al-Helou T, Al-Helou Y. Seroprevalence of Toxoplasma gondii, cytomegalovirus, rubella virus and Chlamydia trachomatis among infertile women attending in vitro fertilization center, Gaza Strip, Palestine. Journal of the Egyptian Society of Parasitology, 2010, 40:451-458.

25. Rubella vaccines: WHO position paper. Weekly Epidemiological Record, 2011, 86(29):301-316.

\section{Global measles and rubella strategic plan : 2012-2020}

The Global measles and rubella strategic plan : 2012-2020 builds on years of experience in implementing immunization programmes and incorporates lessons from accelerated measles control and polio eradication initiatives. The Plan stresses the importance of strong routine immunization systems supplemented by campaigns, laboratory-backed surveillance, outbreak preparedness and case management, as well as research and development. It also reminds us that public health is about people, above all, and that our work to build public trust and demand for vaccination is as important as the work to build and maintain measles and rubella vaccine supply and cold chains.

Further information about this and other WHO publications can be found at: http:/ / apps.who.int/bookorders/ anglais/home1.jsp 